\title{
Síndrome de Burnout: um estudo comparativo entre professores das redes pública estadual e particular
}

\author{
Andressa Pereira Lopes \\ Édel Alexandre Silva Pontes
}

\section{Resumo}

O objetivo deste estudo foi analisar se professores da rede pública estadual e professores da rede particular possuem diferentes dimensões de burnout (exaustão emocional, despersonalização e realização profissional), como também procurou verificar se variáveis demográficas, profissionais e laborais associam-se às dimensões de burnout de forma diferenciada nesses dois grupos. A amostra, do tipo conveniência, foi composta por 40 professores do ensino médio e fundamental, 20 da rede pública estadual e 20 da rede particular, sendo esses profissionais exclusivos de cada rede. Foi utilizado como instrumento o Maslach Burnout Inventory (MBI) - forma ED - professores, e um questionário elaborado para estudar as variáveis. Os resultados obtidos revelaram que estatisticamente os dois grupos possuem diferentes dimensões de burnout, como também se verificou que tais dimensões associaram-se às variáveis de forma distinta nesses grupos.

Palavras-chave: Stress ocupacional, professores, ensino público.

\section{Burnout Syndrome: a comparative study between teachers of state and private school systems}

\begin{abstract}
The goal of this study was to investigate whether teachers from state and private schools have different perception of burnout (emotional exhaustion, depersonalization and professional achievement). We also attempt to verify whether the demographic, professional and laborial variables are related to the dimensions of burnout in a differentiated ways in these two groups. The sample is composed of 40 teachers from high school and fundamental teaching, being 20 of them from the state and 20 from the private school. We use the Maslach Burnout Inventory (MBI) - ED-form as a tool for our work. We also apply a questionnaire designed to study the variables. The results reveal that statistically the two groups have different perceptions of burnout. However, such perceptions are associated with the variables in a distinct way in these groups.
\end{abstract}

Keywords: Occupational stress, teachers, public school education.

\section{Síndrome de Burnout: un estudio comparativo entre profesores de las redes pública estatal y particular}

\begin{abstract}
Resumen
El objetivo de este estudio fue analizar si profesores de la red pública estatal y profesores de la red particular poseen diferentes dimensiones de Burnout (agotamiento emocional, despersonalización y realización profesional), como también buscó verificar si variables demográficas, profesionales y laborales se asocian a las dimensiones de Burnout de forma diferenciada en esos dos grupos. La muestra, del tipo conveniencia, fue compuesta por 40 profesores de de la enseñanza primaria y secundaria, 20 de la red pública estatal y 20 de la red particular, siendo estos profesionales exclusivos de cada red. Fue utilizado como instrumento el Maslach Burnout Inventory (MBI) - forma ED - profesores, y un cuestionario utilizado para estudiar las variables. Los resultados obtenidos revelaron que estadísticamente los dos grupos poseen diferentes dimensiones de Burnout, como también se verificó que tales dimensiones se asociaron a las variables de forma distinta en estos grupos.
\end{abstract}

Palabras-clave: Estres ocupacional, profesores, enseñanza en la escuela pública. 


\section{Introdução}

Nos dias atuais, estar inserido no mercado de trabalho significa fazer parte de uma classe privilegiada, que lutou para conseguir um emprego e que luta constantemente para permanecer nele. Uma sociedade guiada por valores capitalistas impõe um ritmo de competitividade, sobrecarga e estresse no cotidiano das pessoas que trabalham. Seja qual for a área, seja qual for a função, os tempos de hoje exigem muito do trabalhador. $\mathrm{O}$ trabalho proporciona uma identidade ao indivíduo. Por um lado, ele pode ser uma atividade prazerosa, que leva à independência e à realização pessoal; mas, por outro, pode transformar-se em uma atividade geradora de conflitos, desmotivação e doença.

A Síndrome de Burnout é o reflexo do trabalho como forma de desprazer. Em virtude disso, a legislação brasileira, com a Lei $n^{\circ}$ 3.048/99 (Lei que regulamenta a Previdência Social), contempla a Síndrome de Esgotamento Profissional (burnout) como doença do trabalho.

Benevides-Pereira (2003) afirma que é devido a Freudenberger e a Maslach \& Jackson, nas respectivas décadas de 70 e 80, a difusão do termo e dos estudos sobre a Síndrome de Burnout. Dessa forma, observa-se que esta síndrome não é um fenômeno novo, mas que está tendo significativa repercussão atualmente, devido à quantidade de pesquisas científicas que estão sendo feitas relacionando a síndrome com diversas profissões.

Burnout é uma expressão inglesa que significa "perder o fogo", "perder a energia". Existem várias definições e modelos/abordagens acerca da Síndrome de Burnout.

Segundo Carlotto e Palazzo (2006), a definição de Maslach e Jackson sobre a Síndrome de Burnout é a mais aceita. Benevides-Pereira (2002) afirma que essa perspectiva é a mais adotada, devido à grande repercussão do $\mathrm{MBI}$, um instrumento elaborado por Maslach e Jackson, que avalia três dimensões: exaustão emocional, despersonalização e falta de realização profissional. A exaustão emocional é caracterizada pela perda de energia e entusiasmo na prática profissional. A despersonalização caracteriza-se por tratar de maneira distante os colegas, clientes e todos os envolvidos na organização endurecimento afetivo, "coisificação" da relação. Finalmente, a falta de realização no trabalho caracteriza-se quando o trabalhador se sente insatisfeito com seu desempenho profissional, avaliando-se de forma negativa.

Apesar da falta de consenso em relação à teoria e à definição referente à Síndrome de Burnout, a maioria dos autores concorda em dois pontos em relação à suscetibilidade à Síndrome de Burnout. Benevides-Pereira (2002) afirma que o primeiro ponto é quando se referem aos profissionais que trabalham diretamente com pessoas, tendo que a todo o momento assisti-las. O segundo ponto é em relação ao caráter laboral, sendo este um processo que se dá em resposta à cronificação do estresse ocupacional e traz consequências negativas individuais, profissionais, familiares e sociais (Benevides-Pereira, 2003).

O estudo sobre a Síndrome de Burnout em professores vem crescendo e chamando a atenção dos pesquisadores (Silva e Carlotto, 2003). No Brasil, um estudo feito pela Universidade de Brasília (UnB) com trabalhadores da educação - professores, funcionários e especialistas da educação da rede pública estadual de todo o país - mostra que $48 \%$ dos entrevistados apresentavam algum sintoma da síndrome. Nos Estados Unidos, a situação é tão grave que as companhias de seguro americanas consideram a profissão de professor como de alto risco (Bock e Sarriera, 2006).

Muitos estudiosos têm buscado identificar as causas do burnout em professores. Faber (conforme citado por Carlotto, 2002) parte da ideia das causas como uma combinação de fatores individuais, organizacionais e sociais, havendo, dessa forma, uma interação que produziria uma percepção de baixa valorização profissional, tendo como resultado o burnout. Já para Maslach e Jackson (conforme citado por Carlotto, 2002), os professores têm um nível de expectativa muito grande que não pode ser totalmente preenchido. Segundo Cabrera e Elvira (2004), as variáveis sociodemográficas e variáveis relacionadas com as atitudes e a personalidade do sujeito são fatores que estão relacionados com a etiologia do burnout; e também a relação com o aluno tem sido apontada como uma das maiores causas (Carlotto, 2002). Codo e Vasrques-Menezes (1999) relatam que muitas pesquisas apontam os problemas de indisciplina na escola como um dos fatores causadores de burnout, bem como a violência, pais omissos, classes superlotadas, falta de autonomia, salários inadequados, falta de perspectiva de ascensão na carreira são alguns fatores que têm se apresentado associados ao burnout.

A escola é uma instituição essencial na estrutura de qualquer sociedade. Ela é uma comunidade que tem como missão auxiliar na formação de seus indivíduos.

Demo (2007) aponta uma considerável distância entre a escola pública e particular no Brasil. Para esse autor, a escola particular é gerida pela iniciativa privada com base na pressão do mercado e dos pais dos alunos, professores não estáveis, pressão contra greves e funcionamento sistemático mais ou menos confiável.

Soratto e Oliver-Heckler (1999) relatam que a escola pública segue o modelo do serviço público, que é vertical e de hierarquia de linha, ou seja, o poder para se tomar decisões na escola é fragmentado. Silva e Carlotto (2003) acrescentam relatando que o trabalho dos professores geralmente é realizado sob alguns fatores potencialmente estressores como: baixos salários, escassos recursos materiais e didáticos, classes superlotadas, tensão na relação com alunos, excesso de carga horária, inexpressiva participação nas políticas e no planejamento institucional e falta de segurança no contexto escolar.

"Em ambos os sistemas, a atividade fundamental é 'dar aula e prova' em ambiente prevalente instrucionista, ou seja, reprodutivo" (Demo, 2007, p. 182).

Esteve (1999) afirma que o ensino de qualidade existe, nos locais onde existe, devido a um voluntarismo de alguns professores que, frente à tentação do abandono e da demissão, expressam entusiasmo e energia, suprindo, dessa forma, a falta de recursos. 
Diante do exposto, o estudo teve como objetivo verificar as hipóteses: $\mathrm{H} 1$ existe diferença entre as dimensões de burnout nos professores das redes pública estadual e particular de ensino; $\mathrm{H} 2$ variáveis demográficas, profissionais e laborais associam-se às dimensões de burnout de forma diferenciada em professores da rede pública estadual e particular de ensino.

\section{Método}

\section{Participantes}

O estudo teve, como amostra de conveniência, 40 professores, dentre os quais 26 homens e 14 mulheres, que lecionam em escolas públicas e particulares da cidade de Maceió. Foram selecionados 20 professores de cada sistema de ensino, sendo esses grupos exclusivos de cada rede, ou seja, não participaram da pesquisa professores que tivessem vínculos com as duas instituições simultaneamente.

As escolas particulares são instituições de referência de ensino de qualidade e situam-se em regiões nobres da cidade. Quadro oposto do que acontece com as escolas públicas estaduais.

\section{Instrumentos}

Aplicou-se um questionário que foi elaborado com a finalidade de atingir um dos objetivos do estudo. Nele havia questões referentes às variáveis demográficas, profissionais e laborais.

O Maslach Burnout Inventory (MBI) - forma ED professores, foi o segundo instrumento utilizado na pesquisa. Ele foi utilizado para avaliar a Síndrome de Burnout. De acordo com Silva e Carlotto (2003), este instrumento foi traduzido para a língua portuguesa e validado por Benevides-Pereira (2002). Esse inventário é autoaplicado e avalia como o sujeito vivencia o trabalho em três dimensões estabelecidas pelo modelo de Maslach: exaustão emocional ( 9 itens), Realização Profissional (8 itens) e Despersonalização (5 itens), totalizando 22 itens. Foi utilizado o sistema de pontuação de 1 a 5, também usado por Tamayo na adaptação brasileira do instrumento, pois foi verificado que os sujeitos apresentavam dificuldade em responder muitos itens dos instrumentos, devido à especificidade dos critérios da escala original. Dessa forma, empregou-se: 1 para "nunca", 2 para "algumas vezes ao ano", 3 para "algumas vezes ao mês", 4 para indicar "algumas vezes na semana" e 5 para "diariamente".

As propriedades psicométricas do $\mathrm{MBI}$ foram comprovadas em vários estudos. A consistência interna das três dimensões do inventário é satisfatória, apresentando um alfa de Cronbach que vai de 0,71 a 0,90 (Carlotto, 2002). Benevides-Pereira (2002) refere que o $\mathrm{MBI}$ possui validação fatorial (itens com saturação acima de 0,40), consistência interna $(E E=a$ de 0,$90 ; D E=a$ de 0,79 e $R P=a$ de 0,71$) e$ validação convergente.

\section{Procedimento}

Inicialmente, foi realizado um contato com a direção das escolas e com a orientadora pedagógica de cada instituição para apresentar o objetivo do estudo, a fim de obter a autorização e o apoio para a aplicação dos instrumentos. Após o consentimento, foi utilizado o intervalo de trinta minutos para explicar a pesquisa aos professores e saber quem gostaria de participar. Depois que os professores aceitaram fazer parte do estudo, foi aplicado o questionário cujo propósito foi levantar as variáveis demográficas, profissionais e laborais, seguido do Maslach Burnout Inventory $(\mathrm{MBI})$ - forma $\mathrm{ED}$ - professores.

\section{Resultados}

O Banco de Dados foi digitado no Microsoft Office Excel 2003. Foram calculadas medidas descritivas, desviospadrão (DP) e foi utilizado o teste t de Student e de correlação de Pearson.

Através da análise descritiva, delineou-se o perfil dos sujeitos da pesquisa.

Verifica-se que os professores da rede pública estadual são $65 \%$ do gênero feminino e $35 \%$ do gênero masculino, possuem idade média de 44 anos, concentrando-se na faixa de 41 a 50 anos; $80 \%$ são casados e $20 \%$ solteiros. Os professores da rede particular são 95\% do gênero masculino e $5 \%$ do gênero feminino, possuem idade média de 37 anos, concentrando-se na faixa de 31 a 40 anos, $85 \%$ são casados, $10 \%$ são solteiros e $5 \%$ não informaram.

Em relação à variável profissional, os professores da rede pública estadual lecionam para uma média de 7,85 turmas $(D P=3,5)$ e possuem uma média de 15,25 anos $(\mathrm{DP}=10,20)$ de experiência profissional. Os professores da rede particular ensinam para uma média de 14,3 turmas, $(D P=7,16)$ e possuem uma média de 13,1 anos $(D P=8,81)$ de experiência profissional.

No perfil laboral desses profissionais, no item "O que mais dificulta o exercício profissional” (Tabela 1), os professores da rede pública estadual tiveram como respostas mais frequentes: barulho em sala de aula $(23,4 \%)$ e falta de interesse dos alunos (41,6\%). Quanto à frequência de satisfação no trabalho, 10\% respondeu "raramente"; $50 \%$, "às vezes"; $35 \%$, "freqüentemente"; e $5 \%$, "sempre". Na rede particular, a resposta mais frequente dos participantes foi a falta de interesse dos alunos (16\%) e em relação à frequência de satisfação no trabalho, 10\% respondeu "raramente"; $25 \%$, "às vezes"; $30 \%$, "freqüentemente"; e $35 \%$, "sempre".

No que diz respeito aos resultados de burnout, verifica-se, através do teste t de Student $(\alpha=0,05)$, que os professores da rede pública estadual apresentam índices médios estatisticamente maiores $(2,93)$ que os professores da rede particular $(2,53)$ em exaustão emocional $(p=$ 0,000562977). Em relação à despersonalização, não houve diferença estatisticamente significativa nas médias: 1,6 nos professores da rede púbica estadual e 1,71 na rede particular de ensino ( $p=0,379776)$. Já em relação à 
Tabela 1. O que mais dificulta o exercício profissional do professor

\begin{tabular}{|l|c|c|c|}
\hline O que mais dificulta o exercício profissional / Escola & Pública & Particular & Total \\
\hline Barulho & $12(66,7 \%)$ & $6(33,6 \%)$ & $18(23,4 \%)$ \\
\hline Salário & $7(77,8 \%)$ & $2(22,2 \%)$ & $9(11,7 \%)$ \\
\hline Condições físicas & $7(100 \%)$ & 0 & $7(9 \%)$ \\
\hline Falta de interesse dos alunos & $16(50 \%)$ & $16(50 \%)$ & $32(41,6 \%)$ \\
\hline Falta de material didático & $5(100 \%)$ & 0 & $5(6,5 \%)$ \\
\hline Outros & $4(100 \%)$ & 0 & $4(5,2 \%)$ \\
\hline Todos & $2(100 \%)$ & 0 & $2(2,6 \%)$ \\
\hline Total & $53(68,8 \%)$ & $24(31,2 \%)$ & $77(100 \%)$ \\
\hline
\end{tabular}

Fonte: Elaboração dos autores

Tabela 2. Comparação das dimensões de burnout por rede de ensino

\begin{tabular}{|c|c|c|c|c|c|}
\hline Dimensões & Escola & Média & Variância & Stat $t$ & $P(T<=t)$ bi-caudal \\
\hline Exaustão Emocional & $\begin{array}{l}\text { Pública } \\
\text { Particular }\end{array}$ & $\begin{array}{l}2,93 \\
2,53\end{array}$ & $\begin{array}{l}1,388 \\
1,077\end{array}$ & 3,48 & 0,000562977 \\
\hline Despersonalização & $\begin{array}{l}\text { Pública } \\
\text { Particular }\end{array}$ & $\begin{array}{c}1,6 \\
1,71\end{array}$ & $\begin{array}{l}0,848 \\
0,713\end{array}$ & $-0,88$ & 0,379776 \\
\hline Realização Profissional & $\begin{array}{l}\text { Pública } \\
\text { Particular }\end{array}$ & $\begin{array}{l}3,39 \\
3,84\end{array}$ & $\begin{array}{l}0,943 \\
0,690\end{array}$ & $-4,50$ & 9,6589E-06 \\
\hline
\end{tabular}

Fonte: Elaboração dos autores

Tabela 3: Matriz de correlação entre a variável demográfica e as três dimensões de burnout de acordo com cada rede de ensino (EE: Exaustão Emocional, DE: Despersonalização, RP: Realização Profissional). (Os valores abaixo da diagonal correspondem aos professores da rede pública estadual e os acima, aos professores da rede particular.)

\begin{tabular}{|l|c|c|c|c|c|}
\hline & EE & DE & RP & Idade & $\begin{array}{c}N^{\circ} \text { de } \\
\text { Filhos }\end{array}$ \\
\hline EE & $\mathrm{x}$ & 0,27 & $-0,55$ & $-0,39$ & $-0,11$ \\
\hline $\mathrm{DE}$ & 0,27 & $\mathrm{X}$ & $-0,40$ & $-0,14$ & $-0,08$ \\
\hline $\mathrm{RP}$ & 0,03 & $-0,23$ & $\mathrm{X}$ & 0,21 & $-0,1$ \\
\hline Idade & $-0,16$ & $-0,19$ & $-0,45$ & $\mathrm{x}$ & 0,77 \\
\hline $\mathrm{N}^{0}$ de filhos & $-0,10$ & $-0,27$ & $-0,02$ & 0,36 & $\mathrm{x}$ \\
\hline
\end{tabular}

Fonte: Elaboração dos autores

realização profissional ( $p=0,0000096589)$, os professores da rede pública estadual apresentam índices médios estatisticamente mais baixos $(3,39)$ que os professores da rede particular $(3,84)$ (Tabela 2$)$.

Por meio da análise de correlação de Pearson, foi identificada associação estatisticamente negativa da idade $(r=-0,39)$ com a dimensão de exaustão emocional nos professores da rede particular, ou seja, quanto maior a idade, menor será a exaustão emocional. Nos professores da rede pública estadual, houve associação estatisticamente negativa entre idade $(r=-0,45)$ e a dimensão "realização profissional", ou seja, quanto maior a idade, menor o sentimento de realização profissional (Tabela 3).

Foi verificada nos professores da rede particular uma associação positiva e significativa entre número de turmas $(r=0,50)$ e carga horária $(r=0,61)$ em relação à dimensão "exaustão emocional", indicando que: quanto maior o número de turmas e a carga horária do professor, maior a 
Tabela 4: Matriz de correlação entre a variável profissional e as três dimensões de burnout de acordo com cada rede de ensino (EE: Exaustão Emocional, DE: Despersonalização, RP: Realização Profissional). (Os valores abaixo da diagonal correspondem aos professores da rede pública estadual e os acima aos professores da rede particular).

\begin{tabular}{|l|c|c|c|c|c|c|}
\hline & EE & DE & RP & $\begin{array}{c}N^{\circ} \text { de } \\
\text { turmas }\end{array}$ & $\begin{array}{c}\text { Tempo } \\
\text { de ensino }\end{array}$ & $\begin{array}{c}\text { Carga } \\
\text { horária }\end{array}$ \\
\hline $\mathrm{EE}$ & $\mathrm{x}$ & 0,27 & $-0,55$ & 0,50 & $-0,25$ & 0,61 \\
\hline $\mathrm{DE}$ & 0,27 & $\mathrm{x}$ & $-0,40$ & 0,25 & $-0,01$ & 0,25 \\
\hline $\mathrm{RP}$ & 0,03 & $-0,23$ & $\mathrm{x}$ & $-0,12$ & 0,22 & $-0,25$ \\
\hline $\mathrm{N}^{\circ}$ de turmas & $-0,07$ & 0,24 & $-0,19$ & $\mathrm{x}$ & 0,01 & 0,57 \\
\hline Tempo de ensino & $-0,29$ & $-0,42$ & $-0,04$ & $-0,05$ & $\mathrm{x}$ & $-0,08$ \\
\hline Carga horária & $-0,06$ & 0,08 & $-0,20$ & 0,28 & $-0,08$ & $\mathrm{x}$ \\
\hline
\end{tabular}

Fonte: Elaboração dos autores

Tabela 5: Matriz de correlação entre a variável laboral e as três dimensões de burnout de acordo com cada rede de ensino (EE: Exaustão Emocional, DE: Despersonalização, RP: Realização Profissional). (Os valores abaixo da diagonal correspondem aos professores da rede pública estadual e os acima aos professores da rede particular)

\begin{tabular}{|l|c|c|c|c|c|c|c|}
\hline & $\mathrm{EE}$ & $\mathrm{DE}$ & $\mathrm{RP}$ & $\begin{array}{c}\text { Satisfação no } \\
\text { Trabalho }\end{array}$ & $\begin{array}{c}\text { Relação } \\
\text { colega }\end{array}$ & $\begin{array}{c}\text { Relação } \\
\text { aluno }\end{array}$ & $\begin{array}{c}\text { Satisfação } \\
\text { salário }\end{array}$ \\
\hline $\mathrm{EE}$ & $\mathrm{X}$ & 0,27 & $-0,55$ & $-0,56$ & $-0,50$ & 0,11 & $-0,32$ \\
\hline $\mathrm{DE}$ & 0,27 & $\mathrm{x}$ & $-0,40$ & $-0,25$ & $-0,37$ & $-0,39$ & $-0,16$ \\
\hline $\mathrm{RP}$ & 0,03 & $-0,23$ & $\mathrm{x}$ & 0,62 & 0,49 & 0,30 & 0,15 \\
\hline $\begin{array}{l}\text { Satisfação no } \\
\text { trabalho }\end{array}$ & $-0,24$ & $-0,10$ & 0,62 & $\mathrm{X}$ & 0,11 & 0,20 & 0,07 \\
\hline $\begin{array}{l}\text { Relação } \\
\text { colega }\end{array}$ & $-0,12$ & $-0,42$ & 0,29 & 0,17 & $\mathrm{X}$ & 0,11 & 0,40 \\
\hline $\begin{array}{l}\text { Relação } \\
\text { aluno }\end{array}$ & $-0,003$ & $-0,54$ & 0,17 & $-0,01$ & 0,31 & $\mathrm{x}$ & 0,21 \\
\hline $\begin{array}{l}\text { Satisfação } \\
\text { salário }\end{array}$ & $-0,19$ & $-0,13$ & 0,09 & 0,47 & 0,04 & $-0,18$ & $\mathrm{x}$ \\
\hline
\end{tabular}

Fonte: Elaboração dos autores

tendência de elevação do nível de desgaste emocional. Já nos professores da rede pública estadual, a associação foi estatisticamente negativa entre o tempo de ensino $(r=-0,42)$ e a dimensão "despersonalização", logo: quanto maior o tempo de ensino, menor a tendência a um contato frio e impessoal em relação às pessoas do ambiente de trabalho (Tabela 4).

Foi identificada nos professores da rede particular uma associação estatisticamente negativa e significativa em relação à satisfação no trabalho $(r=-0,56)$, relacionamento com o colega $(r=-0,50)$ e satisfação com o salário $(r=-0,32)$ com a dimensão "exaustão emocional", isso significa que, quanto maior for a satisfação no trabalho e com o salário e a relação com os colegas, menor será o nível de desgaste emocional. Como também, quanto maior a relação com os colegas de trabalho e com os alunos, menor será a tendência de tratá-los de forma fria e impessoal. Nesse caso, as variáveis "relação com o colega e com o aluno" se associaram de forma negativa à dimensão "despersonalização". Ainda nesse grupo, houve uma associação estatisticamente positiva em relação à satisfação no trabalho $(r=0,62)$, relação com o colega $(r=0,49)$ e relação com o aluno $(r$ $=0,30)$ em relação à dimensão "realização profissional". 0 que significa dizer que, quanto maior essa variável, maior é 
o sentimento de realização profissional. Com os professores da rede pública estadual houve associação negativa com o colega $(r=-0,42)$ e com o aluno $(r=-0,54)$ em relação à dimensão "despersonalização"; como também a satisfação no trabalho $(r=0,62)$ associou-se à dimensão "realização profissional" de forma positiva (Tabela 5).

\section{Discussão}

O objetivo inicial da pesquisa foi analisar se havia diferença estatisticamente significativa entre as dimensões de burnout nos professores das redes pública estadual e particular de ensino. Os resultados obtidos comprovam essa primeira hipótese. Os professores da rede pública estadual possuem índices médios estatisticamente maiores em relação à dimensão exaustão emocional e índices médios estatisticamente menores em relação à dimensão realização profissional comparados aos professores da rede particular de ensino. Isso remete a Maslach e Leiter (1999), os quais afirmam que muitos pontos em exaustão emocional e despersonalização e poucos pontos em realização profissional significam que os profissionais estão passando por um desgaste físico e emocional.

A fim de corroborar com os resultados acima, Carlotto (conforme citado por Benevides-Pereira, 2002) afirma que há uma correlação inversa entre burnout e satisfação ocupacional. Os resultados deste estudo mostram que $50 \%$ dos professores do ensino público estadual às vezes sentem-se satisfeitos com o trabalho, diferente dos da rede particular, dentre os quais $30 \%$ apontaram sentirem-se satisfeitos frequentemente e $35 \%$, sempre.

Já a segunda hipótese da pesquisa - se variáveis demográficas, profissionais e laborais associavam-se às dimensões de burnout de forma diferenciada - foi confirmada por meio da correlação de Pearson.

Quando foi analisada a relação entre as dimensões de burnout e as variáveis demográficas, identificou-se uma associação estatisticamente negativa da idade ( $r=-0,39)$ com a dimensão de exaustão emocional nos professores da rede particular. Nos professores da rede pública estadual, houve associação estatisticamente negativa entre idade ( $r=$ $-0,45)$ e a dimensão "realização profissional". Nos resultados desse estudo, professores da rede particular são mais novos que os da rede pública. A idade é um dos agentes estressores que facilita ou inibe o burnout. Muitos estudos observam maior incidência da síndrome em profissionais mais jovens (Benvides-Pereira, 2002). Carlotto (2002) aponta que professores menores de 40 anos apresentam maior risco de incidência de burnout devido às expectativas irrealistas em relação à profissão.

Em relação às variáveis profissionais, foi verificada, nos professores da rede particular, uma associação positiva e significativa entre número de turmas $(r=0,50)$ e carga horária $(r=0,61)$ em relação à dimensão exaustão emocional. De acordo com os resultados, esses profissionais lecionam em uma quantidade maior de turmas que os participantes da outra rede de ensino. Carlotto e Palazzo (2006) apontam que a carga horária é um elemento associado à exaustão emocional; devido ao crescimento do ensino particular, para atender mais alunos, o professor aumenta a carga horária, o que gera exaustão emocional.

Ao analisar a relação entre a variável laboral e as dimensões, observou-se, nos professores da rede particular, uma associação estatisticamente negativa e significativa em relação à satisfação no trabalho $(r=-0,56)$, relacionamento com o colega $(r=-0,50)$ e satisfação com o salário $(r=-0,32)$ com a dimensão "exaustão emocional"; as variáveis "relação com o colega e com o aluno" associaram-se de forma negativa à dimensão "despersonalização". Ainda nesse grupo, houve uma associação estatisticamente positiva em relação à satisfação no trabalho $(r=0,62)$, relação com o colega $(r=$ $0,49)$ e relação com o aluno $(r=0,30)$ em relação à dimensão "realização profissional". Com os professores da rede pública estadual, houve associação negativa relacionamento com o colega $(r=-0,42)$ e relacionamento com o aluno $(r=-0,54)$ em relação à dimensão "despersonalização"; como também a satisfação no trabalho $(r=0,62)$ associou-se à dimensão "realização profissional" de forma positiva. Carlotto e Palazzo (2006) afirmam que a relação professor-aluno é um componente essencial da atividade docente. Logo, pode ser fonte de prazer quando essa relação estabelece-se de forma adequada e satisfatória, ou pode funcionar como elemento de tensão e estresse quando ocorre o contrário. Ainda afirmam que analisar o resultado quanto à despersonalização é de extrema importância para o estudo.

Esse estudo apontou que professores da escola pública estadual possuem maior exaustão e menor realização profissional que os participantes da rede particular. O motivo deste quadro não se sabe. $O$ ideal seria que houvesse mais pesquisas com o objetivo de investigar a etiologia da Síndrome de Burnout nesses profissionais, sendo uma analise por rede de ensino. Também é relevante afirmar que tais resultados não podem ser generalizados, uma vez que a literatura é escassa em relação à comparação entre professores das redes pública estadual e particular, fazendose necessário aprofundar os resultados obtidos.

\section{Referências}

Abreu, K. L., Stoll, I., Ramos, L. S., Baumgardt, R. A., \& Kristensen, C. H. (2002). Estresse ocupacional e Síndrome de Burnout no exercício profissional da psicologia. Revista Psicologia, Ciência e profissão, 22(2), 22-29.

Benevides-Pereira, A. M. T. (Org.). (2002). Burnout: Quando o trabalho ameaça o bem estar do trabalhador. São Paulo: Casa do Psicólogo.

Benevides-Pereira, A. M. T. (2003). O estado da arte do Burnout no Brasil. Revista Eletrônica InterAção Psy, 1(1), 4-11.

Bock, V. R., \& Sarriera, J. C. (2006). O grupo operativo intervindo na Síndrome de Burnout. Psicologia escolar e educacional, 10(1), 31-39. 
Cabrera, J. H., \& Elvira, J.A. M. (2004). Estrés y Burnout en profesores. International Journal of Clinical and Health Psychology, 4(3), 597621.

Carlotto, M. S. (2002). Síndrome de Burnout e o trabalho docente. Revista Psicologia em Estudo, 7(1), 21-29.

Carlotto, M. S., \& Palazzo, L. S. (2006). Síndrome de burnout e fatores associados: um estudo epidemiológico com professores. Cadernos de Saúde Pública, 22(5), 1017-1026.

Codo, W., \& Vasques-Menezes, I. (1999). O que é burnout? Em W. Codo (Org.), Educação: Carinho e trabalho (pp. 237-255). Rio de Janeiro: Vozes.

Delcor, N. S. (2003). Condições de trabalho e saúde dos professores da rede particular de ensino em Vitória da Conquista. Tese de Mestrado, Universidade Federal da Bahia, Salvador, Bahia.

Demo, P. (2007). Escola pública e escola particular: semelhanças de dois imbróglios educacionais. Ensaio: avaliação e políticas publicas em educação, 55(15), 181-206.
Esteve, J. M. (1999). O mal-estar docente: a sala de aula e a saúde dos professores. Bauru, SP: EDUSC.

Galvão, S. (2007). Desânimo geral no trabalho. Viva Saúde, 39(1), 42-45.

Maslach, C., \& Leiter, M. (1999). Trabalho: Fonte de prazer ou desgaste? Guia para vencer estresse na empresa. Campinas, SP: Papirus.

Ministério da Previdência Social. (1996). Decreto 3048/99 do Ministério da Previdência Social. Brasília: MPS.

Silva, G. N., \& Carlotto, M. S. (2003). Síndrome de Burnout: Um estudo com professores da rede pública. Psicologia Escolar Educacional, 7(2), 145-153.

Soratto, L., \& Oliver-Heckler, C. (1999). Educação: carinho e trabalho. Em W. Codo (Org.), Escola: uma organização multiprofissional (Vol. 1, pp. 122-138). Petrópolis, RJ: Vozes.
Recebido em: 20/12/2008

Reformulado em: 29/11/2009

Aprovado em: 14/12/2009

\section{Sobre os autores}

Andressa Pereira Lopes (andressa_lopes@hotmail.com)

Centro de Estudos Superiores de Maceió

Édel Alexandre Silva Pontes (alexandrepontes_al@hotmail.com)

Centro de Estudos Superiores de Maceió.

\section{Correspondência}

Andressa Pereira Lopes

Rua dos coqueiros, 103 Condomínio Jardim do Horto. Bairro: Gruta de Lourdes. Maceió - Al CEP: 57052-556.

\section{Agradecimento}

Projeto de Pesquisa de iniciação científica do Programa Semente de Iniciação Científica - PSIC, da Fundação Educacional Jayme de Altavilla - FEJAL. 